\title{
Entre Gramsci e Maquiavel pedagogo: os perigos dos professores de História
}

Between Gramsci and Maquiavel Pedagogo: the dangers of history teachers

\author{
João Carlos Escosteguy Filho*
}

\begin{abstract}
RESUMO: O presente artigo busca, a partir do referencial gramsciano, refletir sobre suas potencialidades para um ensino de história mais significativo e emancipador. Para isso, parte-se da contextualização das críticas mais recentes que o ensino de história vem sofrendo, a partir da ascensão de certo bloco intelectual à direita no cenário político brasileiro, para se compreender o fenômeno dos ataques ao pensamento de Gramsci, tido como mentor intelectual de processos de "doutrinação escolar". A principal fonte dessas críticas é simbolizada pelo movimento Escola sem Partido e pelo livro "Maquiavel Pedagogo" (2013), que levaram ao extremo a associação dos professores, notadamente os de história, a doutrinadores que visam a destruir os valores familiares de alunas e alunos. Partindo-se dessas bases, busca-se, no pensamento de Gramsci, algumas sementes de resistência e algumas possíveis respostas a esses ataques.

Palavras-chave: Gramsci; ensino de história; Maquiavel Pedagogo.
\end{abstract}

ABSTRACT: The present article seeks, based on the gramscian framework, to reflect on its potential for a more meaningful and emancipatory history teaching. For that, it starts from the contextualization of the most recent criticisms that history teaching has been suffering, from the rise of a certain intellectual block to the right in the Brazilian political scene, to understand the phenomenon of attacks on Gramsci's thought, considered as a mentor intellectual process of "school indoctrination". The main source of these criticisms is symbolized by the Escola sem Partido movement and the book "Maquiavel Pedagogo" (2013), both which have taken the association of teachers, notably those of history, to indoctrinators who aim to destroy the family values of pupils and students. Starting from these bases, we search, in Gramsci's thought, some seeds of resistance and some possible responses to these attacks.

Keywords: Gramsci, history teaching, Maquiavel Pedagogo.

Poucos autores têm sido alvo de tantos ataques por grupos situados mais à direita do espectro político quanto Antonio Gramsci' ${ }^{1}$ No Brasil, em especial, Gramsci foi elevado, principalmente por grupos como o "Escola sem Partido", à condição de grande responsável, ao lado de Paulo Freire, não apenas pelo "desastre educacional brasileiro", mas também destacado como grande matriz teórica de um intrincado plano de "dominação esquerdista" da nação. A partir dessa

\footnotetext{
* Doutor em História. Professor efetivo do Instituto Federal de Educação, Ciência e Tecnologia do Rio de Janeiro (IFRJ), campus Pinheiral. Tutor à distância do curso de graduação em História da Unirio, oferecido via Cederj, modalidade semi-presencial, na disciplina História da Historiografia Brasileira, desde 2012/2.Email: joao.filho@ifrj.edu.br ORCID: http://orcid.org/0000-0003-1491-5263

${ }^{1}$ Para fins deste artigo, entenderemos "direita" em uma dimensão mais ampla, inspirado principalmente em BOBBIO (2001, p. 111-125), para quem esse grupo abarca, em especial, os críticos mais ou menos extremados dos ideais de igualdade que têm, por sua vez, caracterizado historicamente as posições mais à esquerda. No que tange aos propósitos de nossa reflexão, salvo expresso textualmente o contrário, serão considerados como intercambiáveis as posições "liberais", "conservadoras" e "reacionárias"; não por serem sinônimos, mas por terem mais similitudes entre si que distinções, tomando-se como referência o critério de Bobbio.
} 
posição de fundo conspiracionista, que enxerga no revolucionário italiano a matriz de células comunistas que visariam, pelo engodo, à dominação mundial, esses grupos mais à direita vêm aglutinando visões de mundo que têm avançado na implementação de projetos políticos cada vez mais reacionários. Assim, considerando essa relação, é de extrema importância retomar algumas das principais reflexões do revolucionário italiano para uma discussão capaz de melhor compreender o fenômeno da "onda conservadora" que tem produzido, dentre outros resultados, um crescimento do sentimento de "ódio aos professores" (PENNA, 2016b), alçados à categoria de doutrinadores vampirescos da inocente juventude. Em especial os professores de história.

Este texto, assim, tem como principal objetivo trazer à discussão esse conjunto de ataques direcionados a professores e a importância de Gramsci como possibilidade para seu enfrentamento e superação. Sua escrita foi primeiramente inspirada em artigo de Ricardo Salles (2012, p. 211-228), "Gramsci para historiadores", cujo objetivo foi apontar, nos Cadernos do Cárcere, principal conjunto bibliográfico de Gramsci, o esforço intelectual do autor italiano em "desenvolver um quadro teórico, um conjunto de conceitos, procedimentos, buscando obter uma série de resultados significativos no campo disciplinar da História" (SALLES, 2012, p. 212). Aqui, a intenção será discutir como algumas reflexões dos Cadernos, fundamentalmente aquelas presentes no Volume 1 da edição brasileira, podem nos ajudar a compor um quadro teórico, conceitos e procedimentos visando ao enfrentamento e superação, no campo do ensino de história, das críticas que vimos sofrendo. Não se pretende, obviamente, esgotar a temática, mas tão somente levantar algumas questões a partir do referencial gramsciano.

Não se trata, portanto, de um "manual" de qualquer tipo para "usos de Gramsci". Tampouco se trata de analisar como Gramsci entende a questão educacional em si. Tencionamos, aqui, tão somente trazer algumas contribuições gramscianas para refletir sobre como podemos potencializar as discussões sobre ensino de história em uma conjuntura na qual o exercício dessa atividade é cada vez mais ameaçado pelas forças conservadoras no poder. Considerando-se que essa forças partem exatamente de certa leitura de Gramsci para acusar os "perigosos docentes de história", nada melhor do que pensar a resposta a partir do próprio autor italiano, invertendo-se o sentido da acusação e apontando como, de fato, Gramsci pode nos ajudar a ser, docentes de história, muito mais "perigosos". Mas não no sentido do bloco acusatório, evidentemente, mas, sim, por contribuir para o alcance de alguns dos mais profundos objetivos da docência em história.

Dividiremos este artigo em três partes, além destas considerações iniciais.

$\mathrm{Na}$ primeira, apontaremos como a atuação de certo bloco intelectual à direita ${ }^{2}$, em franca ascensão no país ao longo dos últimos anos, tem formado um conjunto que pode ser sintetizado na soma de quatro elementos essenciais: 1) autodefinição como "direita"; 2) construção imagética de qualquer oposição como "esquerda" e "inimiga"; 3) entendimento do campo educacional como "dentro de dominação hegemônica" dessa esquerda; 4) ensino de história como uma arena onde multiplicam-se os "militantes doutrinadores".

Em que pesem as distintas abordagens realizadas pelos intelectuais desse conjunto à direita, todos os principais nomes apontados por pesquisadores da temática de alguma maneira convergiram, em algum momento ao longo dos últimos anos, para praticamente todos os quatro elementos

\footnotetext{
2 Entenderemos, aqui, "bloco intelectual" seguindo a definição gramsciana, isto é, como camadas oriundas de grupos sociais que têm por função construir homogeneidade e consciência para esses grupos (GRAMSCI, 2004, p. 15-32). Dessa forma, intelectuais agem como formuladores/organizadores/difusores das concepções de mundo que sustentam ideologicamente os grupos sociais e visam á criação de condições mais favoráveis á expansão da própria classe social.
} 
acima. Assim, uma linha percorre a trajetória entre a definição como "direita" e a construção ideológica do adversário à esquerda, constituindo o campo educacional, em geral, e o do ensino de história, em particular, espaço fundamental desse enfrentamento político.

Nosso foco recairá, assim, na segunda parte deste artigo, sobre aquela que pode ser considerada a principal fonte persecutória de professores no atual cenário político: o movimento Escola sem Partido (MESP), com especial destaque para uma obra que constitui uma de suas fontes intelectuais: o livro Maquiavel Pedagogo, de Pascal Bernardin. Nossa opção pelo MESP justifica-se porque é exatamente nesse movimento que Gramsci é alçado à condição de símbolo maior dessa doutrinação escolar.

$\mathrm{Na}$ terceira parte, considerando essa centralidade de Gramsci, abordaremos alguns elementos do pensamento gramsciano, presentes no primeiro volume dos Cadernos do Cárcere, edição brasileira, que nos possam auxiliar na reflexão sobre o campo do ensino de história, em especial frente aos ataques do MESP. Nesse sentido, discutiremos a importância do pensamento gramsciano para superação dos principais elementos de crítica do MESP ao ensino de história: a acusação de seu caráter "político" e a interdição que se pretende estabelecer sobre qualquer discussão em sala de aula que possa, de alguma maneira, contrariar as determinações intelectuais-morais oriundas do núcleo familiar do/a estudante.

$\mathrm{Na}$ esteira do processo que Lidiane Rodrigues nomeou "revolução conservadora dos intelectuais” (RODRIGUES, 2018, p. 277-312), o crescimento de certo bloco intelectual midiático à direita, com ampla presença em especial nas redes sociais, valeu-se de uma conjugação de processos que, segundo Chaloub e Perlatto (2016, p. 26-31), pode ser explicada a partir de seis grandes hipóteses 1) como parte de um processo internacional que remonta, pelo menos, aos anos 1980; 2) como parte de um distanciamento temporal em relação à ditadura militar brasileira (1964-1985), que contribuiu para uma melhor aceitação de termos como "direita" no imaginário popular; 3) sustentado por uma maior presença midiática, tanto em espaços tradicionalmente hegemônicos de produção ideológica quanto, e principalmente, nos novos espaços da redes sociais, bem como no mercado editorial brasileiro, tudo contribuindo para enorme capilaridade de suas concepções de mundo; 4) associação, direta ou indireta, com uma série de instituições empresariais e think thanks liberais e conservadoras, como Instituto Liberal, Instituto Millenium, Estudantes pela Liberdade etc.; 5) ocupação de espaços na disputa política produzidos pelo que os autores chamam "sucessos e fracassos" da esquerda hegemônica brasileira, representada pelo Partido do Trabalhadores (PT), no seio do vácuo deixado por oposições tradicionais capazes de articular propostas alternativas; 6) por fim, atendendo à própria crise mais ampla de representação política expressa pela forma-partido, mais em voga principalmente a partir de junho de 2013, quando movimentos autoproclamados "sem partido", "acima da política" ou "além da política" espalharam-se pelo país (indo desde movimentos como o MBL, ainda que vários de seus integrantes se tenham candidatado por partidos tradicionais, a partidos ou políticos intitulados "novos" que se colocam discursivamente acima da "política tradicional").

Ainda segundo os mesmos autores (CHALOUBE e PERLATTO, 2016, p. 33-39), alguns elementos foram essenciais na construção de aproximações no interior desse bloco intelectual à direita. Dentre eles, podem ser destacados o radical "antiesquerdismo”, uma associação da esquerda 
tanto ao PT como componentes inseparáveis e a pretensa superioridade moral e objetividade analítica da direita e uma profunda defesa da meritocracia liberal contra perspectivas mais sociais de mundo, com particular destaque para a ascensão, na cena pública, de minorias historicamente marginalizadas. Esses elementos em destaque se coadunaram com uma perspectiva que apontou Gramsci como eixo articulador de tudo contra o que se deveria lutar em nome de um país mais à direita. Daí a "presença constante, ainda que fantasmagórica" (PUGLIA, 2018, p. 42) de Gramsci como vilão oculto a ser enfrentado.

Não é de hoje que Gramsci surge nos discursos mais à direita como grande alvo intelectual a ser abatido na visão de uma "guerra cultural" em andamento. Ao menos desde os eventos de Maio de 68, na Europa, e do cenário dos anos 1980, na América Latina, intelectuais e movimentos conservadores têm abordado a obra gramsciana num largo espectro, que vai da pura negação combativa à incorporação de suas reflexões para a construção de novos caminhos para a direita. Como indicam Daniela Mussi e Alvaro Bianchi, no contexto de transição das ditaduras latino-americanas para regimes democrático-liberais, tocando em particular no caso argentino (mas aplicável em diversos aspectos para o Brasil),

A luta ideológica revolucionária no continente se desdobrava principalmente em duas direções. Em primeiro lugar, no papel do terceiro-mundismo e do "indigenismo" como concepções histórico-culturais "de agitação antibrancas", ou seja, "que renegam de maneira expressa o descobrimento e o sentido cristão-católico, mariano-missional e greco-romano da Conquista, Civilização e Evangelização dessas terras [latino-americanas]". Em segundo lugar, a luta ideológica se daria com a política de direitos humanos que era apresentada e exercida como "constante preservação, justificação e apoio ao avanço do comunismo". Em outras palavras, a "ideologização" aqui se referia ao fato de que a defesa dos direitos humanos promovida por "grupos de solidariedade", entidades, associações e organismos internacionais, levaria à crítica e mesmo à defesa da criminalização das atitudes repressivas de ditaduras militares no continente. Era uma poderosa "ideologia dos direitos humanos", portanto, que servia na prática para "justificar ou tolerar agentes da subversão". Ou uma política "ideológica", que, no caso da Argentina, assumia uma conotação mítica no movimento forte e expansivo das Mães da Praça de Maio (MUSSI e BIANCHI, 2020, n.p.).

O "gramscismo", como inimigo, servia de eixo aglutinador de uma série de teorias reacionárias que associavam o avanço de discussões a respeito dos direitos humanos, da democratização, do fim dos regimes autoritários etc. a conspirações de esquerda para alcançar o poder, o que acabava por destacar, por oposição, a associação desses grupos à direita à manutenção das ditaduras, das hierarquias com base na naturalização do social e do uso da violência de Estado para tratamento das questões sociais. A elaboração de interpretações à direita do que era entendido como avanço do comunismo encontrava na associação entre esquerda, "gramscismo" e direitos humanos uma simbiose a ser combatida a partir da retomada de valores familiares tradicionais que se inseriam em uma longa luta contra o inimigo revolucionário.

Essencial nessa retomada, como destacam Mussi e Bianchi, seriam a concepção cristã de mundo. Afinal, como mostram os autores a partir de construções interpretativas feitas nos Estados Unidos, a "única barreira entre a hegemonia gramsciana e as consciências das pessoas seria a 'alma cristã'. Destruí-la era seu [da visão gramsciana] principal objetivo.” E, a partir da difusão dessa interpretação na América Latina, complementam:

Em um notório contexto de enfraquecimento da argumentação conservadora a respeito de 
uma suposta ofensiva soviética e terrorista na região, a subversão comunista adquiria outros contornos: por um lado, como difusão do tráfico de drogas; por outro, como expansão da influência de intelectuais de esquerda inspirados pelas ideias de Gramsci, em especial por meio de uma reinterpretação de valores éticos e religiosos (MUSSI e BIANCHI, 2020, n.p.).

Nessa agenda ideológica comum, a crítica ao "gramscismo" não poderia ficar de fora. A partir inicialmente dos trabalhos de intelectuais orgânicos dessa direita midiática que acabaram, em 2018, contribuindo significativamente para a construção do resultado eleitoral de Jair Bolsonaro e de outros que ascenderam no Legislativo e Executivo a partir de aproximação propagandística com o ex-capitão do Exército, Gramsci é mais e mais utilizado como síntese de "planos de dominação esquerdista” contra a civilização - especialmente após a publicação dos trabalhos iniciais de Olavo de Carvalho, símbolo maior originário da crítica a Gramsci no interior desse bloco intelectual (MUSSI e BIANCHI, 2020, n.p.).

O enfrentamento à presença de Gramsci é ainda mais acentuado no campo educacional, como pode ser evidenciado pela análise das relações entre os intelectuais destacados como representantes dessa "nova direita" por Chaloub e Perlatto (2016, p. 25-41) e Puglia (2018, p. 40-54) e o MESP. ${ }^{3}$

Como analisado por Fernando Penna (2017, p. 42), o MESP, a partir de usos de estratégias discursivas fascistas, se apresenta nas redes sociais como instrumento de "descontaminação" das escolas brasileiras, do básico ao superior. Os espaços educativos, segundo o movimento, estariam dominados por "infiltração esquerdista" há "trinta anos" - uma temporalidade que, como destacada por Penna e outros, remete diretamente ao período pós-ditadura militar, construindo uma interpretação do passado no qual uma era de ouro da educação durante o autoritarismo dos militares cedeu lugar a um "vale tudo" repleto de infiltrados que, ainda durante a ditadura, teriam iniciado um largo processo de "doutrinação ideológica" inspirada nas ideias de Paulo Freire e, claro, Gramsci. Na retórica das redes, o MESP aparece como solução contra o "conde Gramsci, o vampiro que vampiriza a educação brasileira com a ajuda de Paulo Nosferatu Freire", ou contra "o famoso carrapato estrela, o Carrapatus gramscii, o parasita ideológico da educação brasileira" (PENNA, 2017, p. 43). Toda essa retórica produz um permanente clima de "ódio aos professores" (PENNA, 2016b, p. 93-100), classificados de maneira difusa como militantes ideológicos e doutrinadores motivados pelos ideais gramscianos.

Ressalte-se que praticamente todos os intelectuais apontados por Chaloub e Perlatto (2016, p. 25-41) e Puglia (2018, p. 40-54), que mobilizaram aquela agenda ideológica e centraram ataques ao pensamento de Gramsci, articulando-o à crítica mais ampla à esquerda (tomada sempre como hegemônica sobre a cultura e o debate público nacional), também compartilharam, em diversas ocasiões, do diagnóstico do MESP acerca dos perigos da "doutrinação esquerdista" nas escolas ainda que nem sempre concordassem que os projetos de lei do Escola sem Partido fossem a solução.

Neste ponto, podemos compreender que a chave de crítica do MESP e do bloco intelectual à direita é a certa concepção de ensino de história. Mas não a qualquer ensino de história. Fundamentalmente a um ensino compromissado com a discussão sobre os problemas político-sociais do tempo presente e voltado para a construção de concepções emancipatórias de sociedade. Fundamentalmente, a um ensino de história comprometido com qualquer concepção de Educação em

\footnotetext{
${ }^{3}$ Os intelectuais destacados no trabalho de Chaloub e Perlatto são: Olavo de Carvalho, Reinaldo Azevedo, Luiz Felipe Pondé, Rodrigo Constantino, Guilherme Fiuza, Marco Antonio Villa, Denis Lerrer Rosenfield e Diogo Mainardi. A esses nomes, Puglia acrescenta Flávio Gordon e Bolívar Lamounier.
} 
Direitos Humanos (EDH) segundo os princípios básicos indicados por Vera Candau (2012, p. 17 34): a construção de uma educação voltada para a formação de sujeitos de direito, uma educação voltada para o favorecimento de processos de "empoderamento" e uma educação voltada para o "nunca mais", entendida esta última como superação das tragédias da violência, do autoritarismo, das desigualdades. Compreende-se, portanto, o medo daquela aliança que Cinthia Araújo chamou atenção entre ensino de história e EDH, uma vez que as demandas desta também encontram espaço nos elementos que tornam não apenas o ensino de história possível, mas revelador de suas maiores potencialidades (ARAÚJO, 2006, p. 62-67).

Os exemplos desse tipo de associação e crítica são vários, desde os argumentos que sustentam a motivação das denúncias dos "doutrinadores" até a posição pública do MESP em relação, por exemplo, à questão dos direitos humanos no Enem, quando o movimento entrou com ação para proibir que fosse zerada a prova de redação de quem desrespeitasse os fundamentos dos direitos humanos, até então um dos critérios definidores da correção. Tal associação fica evidente, ainda, no modo como as questões anteriormente levantadas (ameaça comunista, direitos humanos, doutrinação etc.) são trabalhadas em um livro essencial para a construção da concepção de mundo do MESP. Trata-se de Maquiavel Pedagogo, de Pascal Bernardin (2013).

O livro de Bernardin, publicado originalmente na França em 1995, ainda não foi analisado com a profundidade que merece, tendo em vista sua influência central na construção de uma retórica da "doutrinação comunista" em salas de aula, em associação direta a uma crítica ao papel dos professores, às pedagogias ativas, aos direitos humanos e, principalmente, ao medo familiar de perda de influência moral sobre os filhos, retórica esta que constitui a base da atuação do MESP. Da mesma maneira, Bernardin utiliza, já nos anos 90, termos que acabariam entrando no vocabulário conceitual dessa nova direita midiática, em especial após as eleições de 2018, como "globalismo". Isso por si só já bastaria para que fosse alvo de reflexões mais intensas por parte daqueles e daquelas que se têm debruçado sobre a ascensão do bloco intelectual à direita e, em especial, o MESP. ${ }^{4}$

Por que, então, não foi?

Uma possível hipótese explicativa para esse desinteresse pode ter relação com a pouca importância que o próprio MESP mereceu dos estudos acadêmicos até que se tornasse uma ameaça real a ponto de influenciar decisivamente projetos de lei cerceadores da liberdade de ensinar. Afinal, os "argumentos" do MESP, bem como os de Maquiavel Pedagogo, a respeito da "doutrinação comunista" nas escolas e universidades do Brasil e do mundo, sob patrocínio de instituições "comunistas" como a Unesco, a OCDE e a ONU, encontram absolutamente nenhum respaldo paradigmático em pesquisas no campo das humanidades. Dessa forma, tanto o MESP quanto Maquiavel Pedagogo podem ter sido por muito tempo considerados de pouca importância simplesmente por não atenderem, nas argumentações "desenvolvidas", o mínimo que se espera de uma interlocução científica.

\footnotetext{
${ }^{4}$ Busquei analisar o livro de forma mais ampla em ESCOSTEGUY FILHO, 2020, no prelo. Nas páginas que seguem o ponto que interessa - e que não foi devidamente trabalhado no artigo citado nesta nota por questão de foco - diz respeito ao modo como a obra entende o perigo representado pela relação entre Gramsci, comunismo, direitos humanos e ensino.
} 
Contudo, é preciso reconhecer que tal discurso conseguiu alcançar suficiente consenso social para se constituir em uma ameaça e alimentar ideologicamente boa parte dos grupos que ascenderam eleitoralmente em 2018. Dessa maneira, tal como o MESP vem sendo alvo de análises nos últimos anos, é preciso ter em conta as análises "desenvolvidas" por Maquiavel Pedagogo como ponte para buscar-se a compreensão do fenômeno que se vem abatendo sobre o país em uma perspectiva transnacional.

Sobre as análises do livro em si, escrevi acima "desenvolvidas" entre aspas pois o livro parece adotar como parte de sua própria estratégia argumentativa a ausência de reflexões mais aprofundadas sobre as fontes que apresenta. Assim, se, por um lado, o livro traz uma imensidão de transcrições de documentos e autores - todos, segundo Bernardin, de alguma maneira ligados aos organismos que ele acaba considerando dentro do conceito de "globalistas" -, por outro lado essa profusão de transcrições muitas vezes não é acompanhada de análises aprofundadas, servindo mais como mera ilustração das afirmações do autor do que como objetos de críticas e discussão.

Há, por exemplo, trechos do livro e capítulos que acabam exatamente no fim de transcrições, as quais, assim jogadas de maneira solta, acabam tendo seus significados complementados pelo leitor, uma vez que Bernardin muitas vezes abstém-se inclusive de comentá-las, ainda que brevemente. Há outros capítulos, como o XI, cujo título é “A Europa", que tem a absoluta maioria de suas 8 páginas compostas apenas por transcrições soltas. Como outro exemplo, todo o conteúdo entre as páginas 99 e 102 do livro é composto por transcrições que não são analisadas nem antes, nem depois das citações.

Sugeri tratar-se de estratégia argumentativa por considerar que Bernardin parece contar com o próprio senso comum de sua plateia para a reafirmação daquilo que em Maquiavel Pedagogo surge sempre como alerta, como aviso de incêndio, como tragédia anunciada. Dessa maneira, parece considerar que os documentos apresentados são "autoevidentes", podendo ser plenamente compreendidos em sua literalidade, sem mediações analíticas, contextualizações etc. Frente a campos - o educacional e o das humanidades - que exigem intensamente tanto o refinamento conceitual e o rigor teórico quanto um aprofundado esforço analítico, podemos pensar Maquiavel Pedagogo como uma obra que em seu próprio mecanismo de escrita funciona como um manifesto contra a honestidade intelectual.

Não é assim, evidentemente, que Maquiavel Pedagogo se enxerga. O livro, em resumo, pretende-se um manifesto contra a

revolução pedagógica baseada nos resultados da pesquisa psicopedagógica [que] está em curso no mundo inteiro. Ela é conduzida por especialistas em Ciências da Educação que, formados todos nos mesmos meios revolucionários, logo dominaram os departamentos de educação de diversas instituições internacionais: Unesco, Conselho da Europa, Comissão de Bruxelas e OCDE. (...) Essa revolução pedagógica visa a impor uma "ética voltada para a criação de uma nova sociedade" [nota de rodapé] e a estabelecer uma sociedade intercultural. A nova ética não é outra coisa senão uma sofisticada reapresentação da utopia comunista. (BERNARDIN, 2013, p. 9-10):

Esse trecho inicial resume bem as ideias do livro: o mundo vem sendo vítima há décadas de um projeto de organizações mundiais globalistas que têm como grande objetivo transformas mentes e atitudes de crianças e jovens em prol de um plano de instauração de um novo comunismo. O modo primordial de construção dessa revolução nas mentes é pela escola, que cada vez mais vem tomando o lugar das famílias e introjetando ideias subversivas na mocidade. Destarte, a nova 
pedagogia maquiavélica - daí o título da obra - iniciou um processo de corrosão dos valores familiares, último bastião de resistência contra os projetos de dominação comunista internacional.

Toda a lógica argumentativa é assombrosamente semelhante à retórica do MESP e de boa parte do bloco intelectual à direita que ocupa os espaços midiáticos. No limite, qualquer pessoa que não enxergue as evidências desse projeto já constituiria prova viva de sua perfeita execução, já que toda a estrutura depende de o sujeito-alvo da transformação mental ser, também, incapaz de perceber que está sendo vítima da doutrinação. Eis outro elemento de construção mental que conecta os rumos de Maquiavel Pedagogo e a nova direita, que também vê na ausência de provas a prova da ausência (CHALOUB e PERLATTO, 2016, p. 25-41).

A esta altura, fica também clara a associação entre os elementos estruturantes da concepção presente em Maquiavel Pedagogo e Gramsci. O capítulo VI da obra é explícito: “A revolução cultural e interculturalismo: homenagem a Gramsci" (BERNARDIN, 2013). Como essa "ameaça gramsciana" surge para leitores de Maquiavel Pedagogo? Em especial entrelaçado, como o título do capítulo indica, ao medo do "interculturalismo", no texto entendido como sinônimo de "multiculturalismo". Para Bernardin, esse multiculturalismo introduzido nas escolas é um risco, considerandose que "a cultura francesa é colocada no mesmo nível que as dos povos mais distantes de nós, tanto fisicamente quanto psicologicamente" (BERNARDIN, 2013, p. 67). À citação eurocêntrica (em conexão direta com uma concepção racista de "distância entre povos") segue-se, como sempre, a enxurrada de citações descontextualizadas de documentos especialmente da OCDE, que supostamente indicariam, na evidência da leitura, os planos maquiavélicos.

É assim que, indiretamente, Bernardin critica a "necessidade de ultrapassar os particularismos étnicos se se quer atingir o pleno desabrochamento da personalidade de cada um enquanto homem, no sentido universal dessa palavra." (OCDE, apud BERNARDIN, 2013, p. 68). A abordagem proposta no documento mencionado por Bernardin, com o objetivo de formar "uma identidade cultural nova, aberta, não mais marcada pelo eurocentrismo ou pelo etnocentrismo, ou por um vínculo cego a suas próprias crenças e valores." (Idem, ibidem), que defende a viabilidade do funcionamento das sociedades contemporâneas apenas se "a coexistência de culturas diferentes for possível e se os indivíduos puderem, segundo as circunstâncias e segundo suas necessidades, passar de uma cultura a outra, e mesmo ter acesso a várias culturas" (Idem, ibidem), é apontada como um terror. Diz Bernardin: "Não se poderia reconhecer mais claramente que a educação multicultural visa a uma revolução psicológica cujas consequências são dificilmente avaliáveis." (BERNARDIN, 2013, p. 69).

E assim, frente a uma proposição da OCDE a respeito da forma de educação multicultural, Bernardin responde com um vocabulário que se vem tornando cada vez mais comum no bloco intelectual à direita, em especial naqueles círculos que compõem o governo Bolsonaro: globalismo, fragmentação de culturas (entendidas em uma concepção essencialista) e... George Orwell. Vejamos isso na obra.

Afirma a OCDE, segundo Bernardin:

O programa de educação multicultural toma, à luz dessa reflexão, uma amplitude, e mesmo uma profundidade diversa, pois sua razão de ser não se justifica mais unicamente por argumentos éticos (combater as descriminações produzidas pelo racismo ou etnocentrismo) ou jurídicos (respeitar os direitos do homem), mas também epistemológicos (diferenciar a maneira de pensar, as formas da inteligibilidade e a estrutura do saber). Esse enriquecimento do dispositivo conceptual permite considerar a construção de uma teoria científica da educação multi- 
cultural e, portanto, o desenvolvimento de programas de educação multicultural fundados sobre bases científicas. (OCDE, apud BERNARDIN, 2013, p. 68)

Responde o autor de Maquiavel Pedagogo: "Os meios empregados devem, portanto, estar à altura da aposta (...). Não pode se compreender o interculturalismo a não ser na perspectiva globalista, tal como expressa no Documento de referência da Conferência mundial sobre a educação para todos" (BERNARDIN, 2013, p. 69-70).

E o que o documento indicado por Bernardin apresenta de tão incrivelmente destruidor? Vejamos:

Presentemente, no norte como no sul, os educadores começam a reconhecer a necessidade de considerar a educação numa perspectiva mais mundial. Os programas de educação para o desenvolvimento e de educação mundial contribuem para inculcar nos alunos uma atitude mundialista, ensinando-lhes principalmente a reconhecer e a evitar os preconceitos culturais e a encarar com tolerância as diferenças étnicas e nacionais. Esses programas se esforçam por vincular os grandes problemas às realidades de caráter mundial, principalmente as questões concernentes ao meio ambiente, à paz e à segurança, à dívida internacional, às medidas contra a pobreza, etc., em todos os conteúdos específicos da educação fundamental (Conferência Mundial, apud BERNARDIN, 2013, p. 70).

Para Bernardin, porém, "Esse processo de mundialização deverá se desenrolar até seu resultado lógico: a adoção de uma língua internacional, prelúdio da destruição das culturas e das mentalidades locais" (BERNARDIN, 2013, p. 71). E finaliza indicando que a proposição de uma cultura internacional com uma língua apropriada à intenção refere-se diretamente à novilingua de Orwell em 1984, numa referência a autor muito mobilizado pelo bloco intelectual à direita para indicar os riscos do "perigo comunista".

A relação dessa discussão e das proposições da OCDE com o pensamento de Antonio Gramsci permanece um mistério. Aliás, curiosamente, não há qualquer outra menção direta a Gramsci no livro para além do título desse capítulo e da associação ao "interculturalismo". O nome é jogado sem qualquer outra reflexão, construindo-se ao redor do revolucionário italiano mais uma aura a ser temida que entendida. O nome de Gramsci sintetiza aqui algo a que se deve evitar, interditando-se o debate sempre que possível. Afinal, trata-se do "mentor da destruição da educação ocidental". Gramsci como um símbolo de tudo que deve ser combatido pois representaria um “destruidor de valores". Um lembrete do caráter histórico de nossas formações culturais.

Esse modo de apropriação da figura de Gramsci pode ser comparado com outro elemento de crítica também trabalhado na obra de Bernardin e apropriado por frações do bloco intelectual à direita, incluindo os sustentáculos do MESP. Refiro-me ao papel que os direitos humanos teriam na crítica à "doutrinação escolar esquerdista".

Um indício do modo como Bernardin pensa a questão dos direitos humanos - e que, por associação, também compreender uma dimensão do pensamento do MESP - pode ser apontado no trecho que transcreve e aborda criticamente de um documento de 1964 da Unesco, intitulado "A modificação das atitudes". Embora afirme que "não é o objetivo dessa publicação [da Unesco] (...) [o] que denunciamos, mas sim os métodos empregados para obter esse resultado", Bernardin tampouco tece qualquer juízo positivo acerca desses objetivos. Em relação à crítica, porém, não economiza palavras. Para ele, o documento tem uma "filosofia política claramente manipulatória", que, ao fundamentar "tais práticas", acaba por pressupor "um desprezo absoluto pela liberdade e 
dignidade humanas e pela democracia", já que "visa explicitamente à difusão das técnicas de manipulação.” (BERNARDIN, 2013, p. 39-40).

E o que no documento tanto assustou Bernardin? O trecho por ele transcrito explica. Nele, a Unesco afirma que, perseverando "na sua ação em favor dos direitos do homem", e ainda "na luta contra o preconceito e a discriminação", a instituição "já há tempos considera a importância que tem o estudo da modificação das atitudes para as atividades educativas que visem a combater todas as formas de discriminação." (apud BERNARDIN, 2013, p. 40).

A temática dos direitos humanos e da luta contra preconceito e formas de discriminação constitui poderoso polo a atrair críticas de Bernardin, bem como dos intelectuais do MESP, que acusam tais iniciativas de esconder, por trás das intenções, o perigo da dominação comunista. Desse modo, o autor apresenta como prenúncio do terror, por exemplo, o seguinte trecho do mesmo documento (apud 2013, p.45):

Resumindo os efeitos da educação sobre o preconceito, a discriminação e a aceitação do fim da segregação racial no sul dos Estados Unidos, Tumin, Barton e Burrus (1958) asseveram que um aumento de instrução tende a produzir deslocamentos perceptíveis: a) do nacionalismo ao internacionalismo, no plano político; b) do tradicionalismo ao materialismo, no plano da filosofia social geral; c) do senso comum à ciência, como fontes de provas aceitáveis; d) do castigo à recuperação, na teoria dos regimes penitenciários; e) da violência e da ação direta à legalidade, como meios políticos; f) da severidade à tolerância, em matéria de educação infantil; g) do sistema patriarcal à igualdade democrática, em matéria de relações conjugais; h) da passividade ao ímpeto criador, no que diz respeito aos divertimentos e ao lazer. Esse resumo parece indicar que a educação provoca uma larga e profunda modificação das atitudes sociais em geral, num sentido que deve contribuir ao estabelecimento de relações construtivas e sadias entre os grupos.

Para Bernardin, aparentemente, absurdos como a passagem do senso comum à ciência, do castigo à recuperação, da severidade à tolerância e do sistema patriarcal à igualdade democrática constituem profundo processo de lavagem cerebral que visaria somente à destruição dos valores nacionais (item "a") e tradicionais ("b"). E pouco adiante os mesmos documentos afirmarem a importância de trazer as próprias famílias para a discussão conjunta. Segundo Maquiavel Pedagogo, tudo não passaria de táticas para aproveitarem-se de abertura e modificarem os valores dos próprios pais e mães (2013, p. 43-44). Na verdade, quanto mais livre, mais aberta e mais espontânea for a prática pedagógica junto aos alunos e seus familiares, mais indícios mostraria da revolução psicológica em curso.

Essa revolução psicológica, composta por uma "revolução ética - a subversão dos valores" e por uma "revolução cultural", deveria, portanto, ter sua "nova ética" desmontada de seus elementos constitutivos, que seriam, dentre outros (BERNARDIN, 2013, p. 57-58):

Os direitos humanos (estendidos ao direito social: direito à habitação, à alimentação, ao trabalho etc.); a bioética; os direitos das crianças (temível arma contra a família); a educação para a paz, a concórdia entre as nações, o desarmamento, o civismo pacífico, a fraternidade humana, a consciência da interdependência entre as nações (Unesco); a educação para o meio ambiente (Comissão de Bruxelas, Unesco); a criação de um "mundo mais justo e solidário, pilar da nova ordem internacional" (Parlamento Europeu); a "experiência da vida em uma sociedade multicultural" (Parlamento Europeu; temas similares na Comissão de Bruxelas e na Unesco); a tolerância (Unesco); a "passagem da competição à cooperação" (Unesco);51 o desenvolvimento da consciência política (Parlamento Europeu, Unesco); a "paz no espírito dos homens" 
(Unesco); etc.

Ainda que, abraçados à mais absoluta boa vontade, esticando ao máximo nossas fronteiras éticas e conceituais, possamos considerar que faz parte da luta política e ideológica a disputa pela construção hegemônica de distintos sentidos para os termos em uso, especialmente para aqueles que constituem "significantes vazios" (LACLAU, 2011, p. 67-80), não há qualquer possibilidade de considerar a citação acima uma simples disputa por sentidos para os termos elencados. Pelo contrário: a completa ausência desse tipo de reflexão em Maquiavel Pedagogo produz o choque de se constatar que, na base de documento tão importante para a construção conceitual do MESP, os pontos indicados na citação acima possam ser alvo de crítica não pelos limites possíveis de seu desenho frente a instituições transnacionais comprometidas com os limites do próprio capitalismo, mas, ao invés disso, são atacados justamente por se apresentarem suficientemente radicais mesmo quando atrelados a um mínimo possível de uma convivência democrática.

Em outras palavras: ao tecer sua crítica por aquilo que considera excesso dos organismos elencados, e não por suas ausências e limitações, Bernardin propõe, ainda que nem sempre explicitamente, uma lógica educacional que só pode ser exercida pela violência, pela guerra, pela competição, pela homogeneização cultural e pelo descaso frente a qualquer concepção de Meio Ambiente e de Direitos Humanos. Sob o argumento de que o método de promoção de valores éticos é questionável - ainda que, como admite o autor, seja feito em ambiente de troca, liberdade e de modo não-impositivo - , Bernardin possibilita que o oposto das proposições constitua a norma social, abstendo-se de oferecer qualquer caminho para a superação das opressões, desigualdades, injustiças e violências do mundo em que vivemos. E a maior demonstração disso é que, logo após a enumeração dos itens indicados na citação acima, Bernardin assim analisa a passagem: "percebese aí, sob uma hábil apresentação, a retórica criptocomunista”. (2013, p. 58).

Podemos, assim, sinteticamente, perceber um fio que conecta elementos essenciais desse bloco intelectual à direita que ascende nos espaços midiáticos de discussão, em especial as redes sociais. Esse fio vai desde a autoidentidade "à direita", marcada por um sentimento de profunda inimizade a tudo que é considerado de "esquerda" (e que compreende um arco gigante, muitas vezes sem definição precisa), no limite pregando sua complexa exclusão do cenário público, e chega, finalmente, à identificação da educação como alvo privilegiado para direcionamento de suas forças, uma vez que esta é alçada a espaço de dominação hegemônica pela esquerda, causada, principalmente, pelo exército de professores de história militantes.

Considerando os elementos de aproximação entre ensino de história e EDH, bem como os rechaços, simbolizados pelo MESP, a qualquer interpretação do passado que ressalte elementos ligados a concepções emancipatórias de $\mathrm{DH}$, podemos pensar como Gramsci pode nos auxiliar a enfrentar o fenômeno. Isso implica um movimento inicialmente curioso: ao invés de rechaçar as acusações do MESP de que o ensino de história tem sido "politizado" (o que é absolutamente distinto de "doutrinação", como muitas vezes acaba o MESP associando), sigamos outro caminho e consideramos a seguinte questão: é possível um ensino de história despolitizado? Ou melhor: é possível, ao mesmo tempo, defender uma educação emancipatória e um ensino de história despolitizado?

Observemos que reflexões Gramsci pode nos oferecer para tentar iniciar um caminho de respostas possíveis a essas questões. 
III

Gramsci não é citado em profusão por esse bloco intelectual à direita à toa. Suas reflexões oferecem não apenas uma poderosa ferramenta para pensarmos o crescimento desses grupos, mas também para desenvolvermos respostas.

Afinal, Gramsci oferece um quadro teórico bastante completo para pensarmos as formas de construção de concepções de mundo hegemônicas e contra-hegemônicas. Esse quadro permite um exercício reflexivo dos elementos constituintes dessas concepções de mundo - incluindo aí, e talvez em uma posição de destaque, as formas de interpretação do passado. Numa acepção da obra de Jörn Rüsen, podemos pensar esse conjunto de interpretações da experiência temporal como parte constituinte de nossa "consciência histórica" - isto é, segundo o autor alemão, "a suma das operações mentais com as quais os homens interpretam sua experiência da evolução temporal de seu mundo e de si mesmos, de forma tal que possam orientar, intencionalmente, sua vida prática no tempo" (RÜSEN, 2001, p. 57). Em Rüsen, o campo da consciência histórica é definido por um sistema de operações mentais a que o autor chama simplesmente "narrativa histórica", que pode ser de vários tipos - e não apenas da forma como entendemos "historiografia", isto é, narrativa relacionada a uma "história-ciência" (RÜSEN, 2011, p. 95). Há aqui uma possibilidade de conexão entre as formas pelas quais a consciência histórica é desenvolvida e os modos como projetos políticos mais amplos são implementados. Tal compreensão, ao ampliar o escopo das formas como compreendemos a relação passado-presente-futuro para além dos limites da história-ciência, permite que possamos, em conjunto com a abordagem gramsciana, pensar essas "narrativas históricas" como elementos constituintes de concepções de mundo mais amplas. ${ }^{5}$ Em outras palavras, Gramsci possibilita a expansão de nossa abordagem da "consciência histórica" para apreendê-la como parte integrante de "concepções de mundo" mais amplas, possibilitando-nos questionar como visões sobre o passado sustentam projetos hegemônicos ou que visam a tornar-se hegemônicos, e vice-versa.

Esse potencial se expressa em sua conhecida passagem no Caderno 11, parágrafo 12, de sua mais conhecida obra (GRAMSCI, 1999, p. 93):

É preciso destruir o preconceito, muito difundido, de que a filosofia é algo muito difícil pelo fato de ser a atividade intelectual própria de uma determinada categoria de cientistas especializados ou de filósofos profissionais e sistemáticos. É preciso, portanto, demonstrar preliminarmente que todos os homens são "filósofos", definindo os limites e as características desta "filosofia espontânea", peculiar a "todo o mundo", isto é, da filosofia que está contida: 1) na própria linguagem, que é um conjunto de noções e de conceitos determinados e não, simplesmente, de palavras gramaticalmente vazias de conteúdo; 2) no senso comum e no bom senso; 3) na religião popular e, consequentemente, em todo o sistema de crenças, superstições, opiniões, modos de ver e de agir que se manifestam naquilo que geralmente se conhece por "folclore.

Para Gramsci, afirmar que todos os seres humanos são filósofos implica dizer que todas e todos participam de alguma concepção de mundo, ainda que de forma "espontânea" naquilo que a linguagem, a religião popular e, em especial, o "senso comum" e o "bom senso" contém. A questão deixa de ser uma separação entre filósofos e não-filósofos - o que, no limite, implica uma divisão entre os que teorizam sobre o mundo e os que nele somente agem - e passa a ser determinar o quanto de pensamento/reflexão há em cada ação. Ou, segundo o revolucionário italiano, passa-

\footnotetext{
5 Desenvolvi raciocínio semelhante, porém com foco na história da historiografia oitocentista brasileira, em ESCOSTEGUY FILHO, 2014.
} 
se ao seguinte problema:

é preferível "pensar" sem disto ter consciência crítica, de uma maneira desagregada e ocasional, isto é, "participar" de uma concepção do mundo "imposta" mecanicamente pelo ambiente exterior, ou seja, por um dos muitos grupos sociais nos quais todos estão automaticamente envolvidos desde sua entrada no mundo consciente (...) ou é preferível elaborar a própria concepção do mundo de uma maneira consciente e crítica e, portanto, em ligação com este trabalho do próprio cérebro, escolher a própria esfera de atividade, participar ativamente na produção da história do mundo, ser o guia de si mesmo e não mais aceitar do exterior, passiva e servilmente, a marca da própria personalidade? (GRAMSCI, 1999, p. 93-94)

A questão assim levantada por Gramsci diz respeito essencialmente a dois modos distintos de se conceber a relação entre a própria concepção de mundo e a forma como ela se conecta a concepções de mundo mais amplas. Diz respeito a duas posturas diferentes, das quais nasce uma escolha: ou uma profunda crítica que permita estabelecer os elementos componentes de nossa própria visão de mundo, ou a manutenção da incompreensão, o que significa a manutenção de concepções de mundo desagregadas que impedem uma plena compreensão da realidade social. Afinal, como complementa Gramsci:

Pela própria concepção do mundo, pertencemos sempre a um determinado grupo, precisamente o de todos os elementos sociais que compartilham um mesmo modo de pensar e de agir. Somos conformistas de algum conformismo, somos sempre homens-massa ou homens-coletivos. O problema é o seguinte: qual é o tipo histórico de conformismo, de homem-massa do qual fazemos parte? Quando a concepção do mundo não é crítica e coerente, mas ocasional e desagregada, pertencemos simultaneamente a uma multiplicidade de homens-massa, nossa própria personalidade é compósita, de uma maneira bizarra: nela se encontram elementos dos homens das cavernas e princípios da ciência mais moderna e progressista, preconceitos de todas as fases históricas passadas estreitamente localistas e intuições de uma futura filosofia que será própria do género humano mundialmente unificado. Criticar a própria concepção do mundo, portanto, significa torná-la unitária e coerente e elevá-la até o ponto atingido pelo pensamento mundial mais evoluído. (GRAMSCI, 1999, p. 94, grifos meus)

Podemos transpor a discussão gramsciana para o foco deste texto. A centralidade de Gramsci como ameaça a ser combatida pelo bloco intelectual à direita fica patente quando pensamos no potencial transformador dos trechos anteriormente citados. A plena compreensão do modo como nos inserimos nos "conformismos"; a mera assunção de que somos "homens-massa" (ou "mulheres-massa") de algum conformismo, e que podemos superar essa condição por meio de uma radical reflexão sobre o tipo histórico de conformismo que nos condiciona permite pensar todo o potencial da educação, em geral, e do ensino de história, em particular, para o enfrentamento dessas questões.

Se para Gramsci, o essencial nesse exercício filosófico é a profunda crítica à própria concepção de mundo de modo a torná-la "unitária e coerente", então essa crítica passa por uma ampla reflexão sobre os processos históricos que nos trouxeram até aqui. Não para louvar os feitos passados em nome de uma nostalgia, ou para referendas memórias oficiais. Mas para, à maneira de Benjamin, escovar a história a contrapelo, o que nos permitiria compreender os mecanismos, as estruturas, os condicionantes que nos tornaram o que somos. Não à toa, em Gramsci, essa crítica

Significa também, portanto, criticar toda a filosofia até hoje existente, na medida em que ela 
deixou estratificações consolidadas na filosofia popular. O início da elaboração crítica é a consciência daquilo que é realmente, isto é, um "conhece-te a ti mesmo" como produto do processo histórico até hoje desenvolvido, que deixou em ti uma infinidade de traços acolhidos sem análise crítica. Deve-se fazer, inicialmente, essa análise. (Idem, ibidem).

Um ensino de história comprometido com a superação dessa condição fragmentária deveria ter como condição primeira de sua atuação não a abordagem do passado, mas a poderosa crítica do presente, uma vez que é neste que se manifestam, como "passados que não passam" - isto é, "sobrevivências do passado que se instalam na história e na memória e que insistem e nos fazem ver as experiências como virtualidade atuais" (PEREIRA e SEFFNER, 2018, p. 24). Essas sobrevivências, reiteradas continuamente no presente, atualizam mecanismos passados de exploração e tragédia, de dor e extermínio, impossibilitando, se ignoradas, qualquer ação transformadora que vise à superação dos problemas do presente.

Dessarte, torna-se impossível um ensino de história comprometido com projetos emancipadores de ser humano e do mundo sem a partida do momento presente, das compreensões de seus problemas e, também, claro, sem uma reflexão sobre os modos pelos quais os problemas aparecem para nós. Em outras palavras: sem uma crítica dos mecanismos ideológicos que, a partir de uma desigual distribuição dos poderes econômico, político etc., tornam visíveis certos aspectos da realidade enquanto mascaram outros. Desde a linguagem dos meios de comunicação de massa até os modos pelos quais políticas públicas são construídas, tudo deve fazer parte do universo das aulas de história para que o passado não seja o do antiquarista, mas o do historiador. Afinal, retomando Marc Bloch - haveria o MESP de considera-lo também um esquerdista doutrinador? -, "a incompreensão do presente nasce fatalmente da ignorância do passado. Mas talvez não seja menos vão esgotar-se em compreender o passado se nada se sabe do presente." (BLOCH, 2001, p. 65). Apenas o "contato perpétuo com o hoje" pode, assim, dar conta de um ensino de história prenhe de seus potenciais emancipatórios.

Evidentemente, isso passa longe do que propõem tanto o bloco intelectual à direita quanto o MESP em suas manifestações contrárias à discussão política em salas de aula, em sua defesa de uma pretensa neutralidade do professor ou em sua crítica a qualquer ação pedagógica que contrarie as convicções morais de estudantes oriundas do núcleo familiar. Não à toa, um dos elementos essenciais do MESP para a identificação dos pretensos “doutrinadores" em sala de aula diz respeito a docentes que, nas palavras do movimento, "se desvia[m] frequentemente da matéria objeto da disciplina para assuntos relacionados ao noticiário político ou internacional" (PENNA, 2017, p. 37). Não à toa, para o MESP os filhos e as filhas são considerados propriedades familiares, verdadeiras posses de pais e mães que devem ser mantidos e mantidas sem qualquer desafio às próprias crenças, sem qualquer diálogo em relação às próprias convicções, independentemente de quais sejam (MOURA e SALLES, 2018, p. 157)

Esses dois elementos (questão da política do presente e prole como propriedade familiar) merecem duas outras considerações.

A primeira nos permite retomar Gramsci em sua crítica do conceito de história de Benedetto Croce, questionando se a mesma não teria uma origem "puramente livresca e erudita". E afirma que "somente a identificação entre história e política evita que a história tenha esta característica." A continuação dessa citação, quando utilizada para a reflexão sobre os potenciais do ensino de história, oferece uma abordagem mais ampla para a consideração das relações entre História e Política: 
Se o político é um historiador (não apenas no sentido de que faz a história, mas também no de que, atuando no presente, interpreta o passado), o historiador é um político; e, nesse sentido (que, de resto, aparece também em Croce), a história é sempre história contemporânea, isto é, política. Croce, contudo, não pode chegar a esta conclusão necessária precisamente porque ela conduz à identificação entre história e política e, consequentemente, entre ideologia e filosofia. (GRAMSCI, 1999, p. 312)

Ou bem o professor de história consegue compreender os aspectos políticos de seu fazer pedagógico - e, nesse movimento, já constrói possibilidades para a superação dos elementos fragmentários de sua concepção de mundo -, ou o que restará será o predomínio de uma visão sobre o ensino "puramente livresca e erudita". A história como resposta às demandas da vida humana (de resto, ainda que noutra concepção, também presente como exigência da história em Rüsen) é mais do que um mecanismo para dar sentido ao conhecimento; é parte inseparável da maneira como esse conhecimento pode ser transformador da realidade vivida.

A segunda consideração, que diz respeito à visão da prole como posse de pais e mães, é a que nos permite uma mais plena compreensão dos significados de um ensino de história que se pretenda "emancipador". Como destaca Gert Biesta, o conceito de "emancipação" tem raízes na lei romana, referindo-se ao ato de libertação do filho ou esposa (bem como do servo) da autoridade legal do pater famílias. Isso implica, ainda segundo o autor, que a pessoa-alvo da emancipação se torna independente e livre como resultado do ato de emancipar-se (BIESTA, 2013a, p. 79). Pensar um ensino de história emancipatório, assim, exige de nós, professores, considerar como indispensável o desafio pedagógico de emancipação intelectual de nossos e nossas educandas. No sentido determinado pelo MESP, isso implica inverter a pecha por eles atirada sobre a relação escolar, que é considerada pelo criador do Escola sem Partido, Miguel Nagib, uma relação de cativeiro, já que o aluno e a aluna constituiriam "audiência cativa" (PENNA, 2016a, p. 54).

Essa inversão deve considerar o aspecto de "cativeiro intelectual" que o MESP define para a prole sob domínio familiar. Afinal, se à escola é proibida qualquer atuação no sentido de contrariar, desafiar, questionar crenças discentes oriundas do núcleo familiar, então isso significa considerar alunas e alunos sob absoluta guarda intelectual de seus progenitores.

Um ensino de história emancipatório exige de nós uma tarefa de libertação desse cativeiro intelectual familiar. E isso só é possível por meio de uma relação dialógica e crítica, capaz de construir conjuntamente questionamentos que articulem, exatamente, aquela análise ampla do presente com os elementos do passado que o expliquem. Ainda que isso produza uma "violação da soberania do sujeito" - aliás, segundo Biesta, indispensável elemento constituinte do ato educativo verdadeiramente significativo (BIESTA, 2013b, 46-50).

\section{Considerações finais:}

Este texto pretendeu levantar algumas questões que possam, a partir das reflexões gramscianas, permitir um tensionamento, no campo do ensino de história, de algumas das principais ameaças que ele tem sofrido, notadamente aquelas perpetuadas pelo movimento Escola sem Partido, representadas na obra Maquiavel Pedagogo.

Mais do que um ataque abstrato à história-ciência ou ao seu ensino, o MESP tem como alvo preferencial os profissionais da educação que trabalham a partir de um ensino de história mais 
profundamente compromissado com as questões sensíveis do presente, com a transformação da realidade e a superação de suas mazelas e com uma radical emancipação intelectual de alunas e alunos do cativeiro que lhes é imposto, na ótica do MESP, a partir da relação de posse que devem manter com suas famílias.

Sem dúvida há maneiras de se ensinar história sem afrontar o Escola sem Partido. A questão, contudo, é se tal não constituiria uma mutilação dos potenciais mais transformadores do ensino da disciplina. Afinal, retomando a perspectiva de Araújo (2006), o ensino de história constitui lócus privilegiado para uma articulação com a Educação em Direitos Humanos exatamente porque as questões que lhe servem de motivação existencial - para retomar os termos de Rüsen - são os mesmos que justificam a existência da própria EDH: formação para cidadania, para a democracia, para uma cultura de direitos humanos; formação de sujeitos de direitos, de pessoas empoderadas e para o "nunca mais".

Evidentemente, nenhum desses elementos pode ser essencializado, sob pena de se perder a radical crítica do presente que deve existir, como fundamento, em toda aula de história. Como campo aberto de possibilidades, o presente não se esgota nas manifestações hegemônicas que lhe dão sustentação, mas também existe no devir de cada futuro não realizado do passado; de cada luta; de cada movimento que pressiona por mais e mais expansão da democracia.

Dessa forma, um ensino de história emancipatório diz tanto sobre o passado quanto sobre o presente; busca incessantemente tanto o passado quanto o futuro. A escolha de Gramsci como símbolo de tudo que deve ser extirpado em um projeto hegemonicamente conservador faz todo sentido. Pois o potencial das reflexões gramscianas para o alcance de um processo transformador radical é o que mais assusta os que não podem admitir a ousadia da emancipação.

\section{Referências}

ARAÚJO, Cinthia Monteiro de. Formando sujeitos: as alianças entre o ensino de História e a Educação em Direitos Humanos. Dissertação de mestrado em Educação. Rio de Janeiro: PUC, 2006

ESCOSTEGUY FILHO, João Carlos. Gramsci, Rüsen e a busca por uma "historiografia integral" do oitocentos brasileiro. Revista de Teoria da História. Ano 6, número 11, maio/2014, p. 39-62.

ESCOSTEGUY FILHO, João Carlos. O "belo risco" do ensino de história frente aos medos do movimento Escola sem Partido. Escritas: Revista de História de Araguaína. No prelo. 2020.

BERNARDIN, Pascal. Maquiavel Pedagogo: ou o ministério da reforma psicológica. Campinas, SP: Ecclesia e Vide Editorial, 2013.

BIESTA, Gert. Para além da aprendizagem: educação democrática para um futuro humano. Belo Horizonte: Autêntica Editora, 2013b

BIESTA, Gert. The beautiful risk of education. Boulder: Paradigm Publishers, 2013a

BLOCH, Marc. Apologia da história ou o ofício de historiador. Rio de Janeiro: Jorge Zahar, 2001.

BOBBIO, Norberto. Direita e Esquerda: razões e significados de uma distinção política. $2^{a}$ edição revista e ampliada. São Paulo: Editora Unesp, 2001.

CANDAU, Vera Maria. Educação em direitos humanos no Brasil: gênese, desenvolvimento e desafios atuais. In: PAIVA, Angela Randolpho (org.). Direitos humanos em seus desafios contemporâneos. Rio de Janeiro: ed. PUC-Rio: Pallas, 2012, p. 17-34.

CHALOUB, Jorge. \& PERLATTO, Fernando. 2016. A Nova Direita Brasileira: Ideias, Retórica e Prática Política. Insight Inteligência N 72; Ano XIX; Janeiro/Fevereiro/Março, p. 25-41.

GRAMSCI, Antonio. Caderno do Cárcere, volume 1: Introdução ao Estudo da Filosofia. A filosofia de Benedetto Croce. Civilização Brasileira: Rio de Janeiro, 1999. 
GRAMSCI, Antonio. Caderno do Cárcere, volume 2: Os intelectuais. O princípio educativo. Jornalismo. $3^{a}$ edição. Civilização Brasileira: Rio de Janeiro, 2004.

LACLAU, Ernesto. Emancipação e Diferença. Rio de Janeiro: EdUERJ, 2011.

MOURA, Fernanda Pereira de; SALLES, Diogo da Costa. O Escola sem Partido e o ódio aos professores que formam crianças (des)viadas. Periódicus: revista de estudos interdisciplinares em gêneros e sexualidades, v. 1, n. 9, pp. 136-160, maio-out. 2018.

MUSSI, D.; BIANCHI, A. Os inimigos de Gramsci - Jacobin Brasil, [s.d.]. Disponível em: <https://jacobin.com.br/2020/04/os-inimigos-de-gramsci/>. Acesso em: 29 jul. 2020

PENNA, Fernando de Araujo. O Escola sem Partido como chave de leitura do fenômeno educacional. IN. FRIGOTTO, Gaudêncio (org.). Escola "sem" partido : esfinge que ameaça a educação e a sociedade brasileira. Rio de Janeiro : UERJ, LPP, 2017, p. 35-48.

PENNA, Fernando de Araujo. 0 ódio aos professores. In: AÇÃO EDUCATIVA (org.). A ideologia do movimento Escola sem Partido: 20 autores desmontam o discurso. São Paulo: Ação Educativa, 2016b, p. 93-100.

PENNA, Fernando de Araujo. Programa "Escola sem Partido": uma ameaça à educação emancipadora. In: GABRIEL, Carmen Teresa; MONTEIRO, Ana Maria; MARTINS, Marcus Leonardo Bomfim (orgs.). Narrativas do Rio de Janeiro nas aulas de história. Rio de Janeiro: Mauad X, 2016a, p. 4358.

PEREIRA, Nilton Mullet; SEFFNER, Fernando. Ensino de História: passados vivos e educação em questões sensíveis. Revista História Hoje, v. 7, $n^{\circ}$ 13, p. 14-33, 2018. Disponível em: https://rhhj.anpuh.org/RHHJ/article/view/427/275. Último acesso em 30/05/2019.

PUGLIA, L. S. Gramsci e os intelectuais de direita no Brasil contemporâneo. Teoria e Cultura, v. 13, n. 2, 20 dez. 2018.

RODRIGUES, L. S. Uma revolução conservadora dos intelectuais (Brasil/2002-2016). Política \& Sociedade, v. 17, n. 39, p. 277-312, 29 nov. 2018.

RÜSEN, Jörn. Jörn Rüsen e o ensino de história (organizadores: Maria Auxiliadora Schmidt et al). Curitiba: Ed. UFPR, 2011.

RÜSEN, Jörn. Razão Histórica - Teoria da História: os fundamentos da ciência histórica. Brasília: Editora Universidade de Brasília, 2001.

SALLES, Ricardo. Gramsci para historiadores. In: História da historiografia. Número 10, Ouro Preto, p. 211-218, dez-2012. 